University of Wollongong

Research Online

Faculty of Engineering and Information

Faculty of Engineering and Information

Sciences - Papers: Part B

Sciences

2017

\title{
A Framework of MLaaS for Facilitating Adaptive Micro Learning through Open Education Resources in Mobile Environment
}

\author{
Geng Sun \\ University of Wollongong, gs147@uowmail.edu.au \\ Tingru Cui \\ University of Wollongong, tingru@uow.edu.au \\ Wanwu Guo \\ Central Queensland University (CQU),w.guo@cqu.edu.au \\ Shiping Chen \\ CSIRO ICT Centre, shiping.chen@csiro.au \\ Jun Shen \\ University of Wollongong, jshen@uow.edu.au
}

Follow this and additional works at: https://ro.uow.edu.au/eispapers1

Part of the Engineering Commons, and the Science and Technology Studies Commons 


\title{
A Framework of MLaaS for Facilitating Adaptive Micro Learning through Open Education Resources in Mobile Environment
}

\author{
Keywords \\ facilitating, mlaas, resources, adaptive, education, learning, micro, mobile, environment, open, framework \\ Disciplines \\ Engineering | Science and Technology Studies \\ Publication Details \\ Sun, G., Cui, T., Guo, W., Chen, S. \& Shen, J. (2017). A Framework of MLaaS for Facilitating Adaptive Micro \\ Learning through Open Education Resources in Mobile Environment. International Journal of Web \\ Services Research, 14 (4), 50-74.
}

This journal article is available at Research Online: https://ro.uow.edu.au/eispapers1/591 


\title{
A Framework of MLaaS for Facilitating Adaptive Micro Learning through Open Education Resources in Mobile Environment
}

\author{
Geng Sun ${ }^{1}$, Tingru Cui ${ }^{1}$, William Guo ${ }^{2}$, Shiping Chen ${ }^{3}$ and Jun Shen ${ }^{1}$ \\ 1, University of Wollongong \\ 2, Central Queensland University \\ 3, CSIRO Data61
}

\begin{abstract}
Micro learning becomes popular in online open learning and it is effective and helpful for learning in mobile environment. However, the delivery of open education resources (OERs) is scarcely supported by the current online systems. In this research we introduce an approach to bridge the gap by providing adaptive micro open education resources for individual learners to carry out learning activities in a short time span. We propose a framework for micro learning resource customization and a personalized learner model, which are supported by education data mining (EDM) and learning analysis (LA). A serviceoriented architecture for Micro Learning as a Service (MLaaS) is designed to integrate all necessary procedures together as a complete Service for delivering micro OERs, providing a platform for resource sharing and exchanging in peer-to-peer learning environment. Working principle of a key step, namely the computational decision-making of micro OER adaptation, is also introduced.
\end{abstract}

Keywords: Open Learning, Service Oriented Architecture, Open Education Learning Resource, Micro Learning, Software as a Service

\section{INTRODUCTION}

As more and more universities open up online access to their courses, open education resources (OERs) become more popular in the whole education sector, particularly in tertiary and vocational sectors. According to the latest statistics, millions of people attend the virtual classroom of online open learning (OL) to access such OERs every day, the massive open online course (MOOC) being a famous associated product of OL. In fact, the number of students who are enrolled in a single course at the same time could be upto tens of thousands [1] [2].

OL is recognized as a novel and affective learning way that can lead to a revolution to the traditional way of learning. Nevertheless, delivery effectiveness of OERs to eLearners in diverse learning environments remains a challenge to OL. For example, studies showed that MOOC are currently suffering from low completion rate [3]. Most learners who enroll in MOOC courses eventually dropped out, due to various reasons.

Although educational professionals have strived to the utmost extent on exploring OL, OERs and MOOC format as a regular are barely a complementary pedagogical approach for mobile learning [4]. Having studied the existing literature and development of OL and OERs, we are motivated to carry out a research to provide learners adaptive OERs in terms of micro learning. In other words, we are dedicated to tailor OERs into chunks with relatively short time length and allocate the chosen chunk(s) to learners for the right time span. This approach will be realized by Micro learning as a Service (MLaaS) in the SaaS manner. Following such an optimal way, learners could easily complete the learning process of each unit within fragmented pieces of time. For example, travelling by train on his/her way home from work for 15 minutes, he/she would be able to use mobile devices to learn a piece of OL course within this time. In this case, an ideal course module delivered to him/her should be limited within the time span (e.g. 15 minutes) to ensure a micro but complete learning experience.

The rest of this paper is organized as follows: Section 2 discusses the background of OERs and MOOC and elaborates the research challenges that we are facing; Section 3 introduces the categorization and customization of OERs in the micro learning context; a personalized learner model for micro learning will be demonstrated in Section 4, with associated schemes for discovering patterns and rules for the model construction by leveraging the educational data mining (EDM) and learning analysis (LA); the MLaaS architecture will be shown in Section 5, working principle of the micro OER delivery can be found in Section 6; and finally Section 7 will conclude this paper. 


\section{BACKGROUND}

\subsection{Nature of OERs and MOOC delivery in Mobile Environment}

OL performs quite differently from on-campus e/m-learning mode. OERs are "digital learning resources offered online freely and openly to teachers, educators, students, and independent learners in order to be used, shared, combined, adapted, and expanded in teaching, learning and research." [5]. OL is the combination of informal learning and formal learning. Learners enjoy high flexibilities in online OL because there is no strict time constraint for joining and quitting. Learners engaged in OL are across age groups and culture background with a wide range of geographic distribution.

Generally OERs can be differentiated from MOOC and open courseware (OCW). Contrary to MOOC, OCW only offers course materials rather than entire courses. In other words, OER can be either structured (MOOC content) or unstructured (i.e. OCW), even both of them. OER providers and instructors have tried to promote their courses and affiliated educational products at full stretch. They have leveraged mobile learning (m-learning) for learners to easily participate in learning activities regardless of restrictions in time and location.

From another aspect, mobile learning activities in OL normally consist of two sections: online learning and offline learning [6]. Since mobile learners can freely download materials into their mobile devices for viewing offline, they do not often stay with OL platforms and attend virtual classrooms [7]. In fact, accessing OERs online is only a part of any learning; more tasks associated with any learning would require activities offline [8], such as data collection, data analysis, and report writing for an assignment. Logically, mobile OL is through online systems that include guided and instructional materials, the transaction details and deliverable resources [9]. Hence, while learners are able to accomplish many of their OL tasks offline, for some necessary procedures, such as data entry and work submission, they need to go back online to conduct these specific tasks.

\subsection{Micro Learning}

Research conducted by Yahoo [10] stated that although users seem to be addicted by mobile devices with no willingness to put down their devices, they just want to receive and process information rapidly and quickly. Results of a study [11] reveals that when proceeding m-learning young learners frequently pause their learning activities and transfer their attention to another thing, and commonly the time lasting for their attentions often limited in 15 minutes. In addition, by analyzing 6.9 million records of video playing, edX found that the videos with a time length less than 6 minutes are more attractive, while students' engagements drop sharply after 6 minutes [12].

Micro learning refers to short-term learning activities on small learning units. Its learning process covers a time span from a few seconds (e.g. in mobile learning) to up to 15 minutes. In the contemporary web society, micro learning pertains to small pieces of knowledge based on web resources [13]. With mobile devices, quite often learners accomplish learning mission in a short time period. According to prior study [14], micro learning can be defined by the assumption that short time span is needed to complete a relevant learning task. Hence, micro learning booms with the wide use of mobile devices, and it becomes a major learning means in mobile environment. Micro learning shares some similar characteristics with mobile learning as both are individually referable, self-contained, reusable and remixable [15].

Micro learning resources are available on-demand to facilitate just-in-time learning [16]. These small learning bytes are not only feasible to be learnt on-the-go, but also require less effort and aid quick assimilation, thus reducing the dependency on a fixed time slot or the need to take a large chunk of time out of one's working day [10]. As micro learning evolves, micro-content delivery with a sequence of micro interactions enables users to learn without information overload [16]. It is a key technology to ensure better learning results in terms of retention of propositional content [14].

\subsection{Research Challenges}

Some researchers doubt that open online courses and OER delivery may not reach its promises because many aspects of traditional classes, such as small-group discussions and face-to-face interactions with instructors, do not work in the open online format [17]. OER makes information available to people at any time, at any place, and in any form, but the key challenge is to not only transmit the right contents at the right time but also actually do it in the right way. OER providers have recognized that current OL platforms can neither guarantee learners to enjoy their learning experience, nor receive timely feedback of their learning results in an open and connected environment. Several key areas have been recognized as critical for future blended learning applications: new mobile apps, deeper international expansion 
through translation and geographical partnership distribution, online courses platform to enable thirdparty apps and integrations, and new features to encourage more collaboration among students [18]. OER providers try to ensure that the contents are being presented in a univocal manner, whereas the environment is configurable by the instructors; the courses are easily managed; and the exams are standardized. However, the reality remains unsatisfied since online courses lack proper control, verification, or monitoring of these targets [19].

There are some barriers for course instructors to migrate their previous teaching strategies to this new blended learning environment straightway. Although utilizing mobile cloud-based learning and forthcoming mobile apps bring multiple advantages, learning resources for non-mobile devices cannot be directly adapted to mobile devices because of their indeterminacies of context (e.g. unpredictable network bandwidth), and specificities (e.g. different operation systems).

In some MOOC courses, instructors borrow the principles of micro learning to redesign their courseware and associated settings. Their actions include chunking the course materials and repackaging them in order to make learners easily go through the whole bytes of learning chunks within a short duration which ideally does not exceed the limit of 15 minutes [13]. They prefer to use quizzes or games to link two chunks [12]. However, these efforts are still in the trial format and have not been applied to larger scale OER production and delivery.

MOOC is a subset of OERs, which means that the amount of OER is far more than 'massive'. OER is flourishing with the era of big data. With the users of MOOC reaching millions, relevant data associated with OERs are fast generated and users are continuously in geometric growth. When facing massive options as a result of the exponential increase in learning materials available in OERs, learners may be too puzzled to choose the right courses to learn early or late, especially when they only prepare to make short-term effort at once and have to make a decision immediately.

Micro learning can be used as part of 'push' applications, in which an instructor determines what learning units to deliver when and where, or as 'pull' applications, in which a learner decides when and how to access the learning resources [20]. However, OL is mostly in the distance and online manner while learners are in high geographic diversities. Hence, it is difficulty for OL instructors to provide feedback in a timely manner. Instructors' guidelines cannot fit all learners enrolled in the same course as well.

The problem is even more pronounced in m-learning, as devices themselves may cause distractions such as phone calls, email alerts and social network apps (e.g. Facebook, Twitter and WhatsApp etc.). The average mobile user also has a short attention span - most people skim headlines and prefer bitesize content than long articles.

Disruptions can also come from external environment when learning in movement where unpredictable conditions are more likely to occur. To stand this distracted learning experience, learners need to pay more attentions and reflections. Therefore, learning contents should be able to engage with learners instantly, i.e., to give them contents that they are interested in the first place [21]. Due to the screen size of mobile devices, avoiding cognitive load is necessary by eliminating any unrelated or decorative materials, which only serve to drive learners' attention away from actual information. Moreover, the most important information needs to be mentioned first or in an obvious place in micro OERs. This can help users absorb the key information even though they are unable to finish a module at a time.

In micro OL, each learning activity is anticipated to be short but complete, and each OER chunk needs to be available as a stand-alone module [22]. In other words, each micro OER must be selfcontaining and can be used independently. Moreover, proposed micro OERs are able to be aggregated, they can be grouped or rejoined into larger collections of content, or clusters with similar topics [23].

Researchers and practitioners are interested in developing artificial intelligence based systems to support adaptive learning [24]. Online learning systems incorporating user data analysis in response to individual student's performance would create adaptive learning environments [25]. There are a few studies, including our pilot work [26], exploring the use of smart systems that implement learning resources adaptation. These efforts focus on university level e/m-learning, without looking into the larger OL scene [27]. It is also found that some measures can be effective to realize adaptive learning for an entire course, but are not workable for the fragmented learning activities because of different time schedules of individual learners during the whole course.

Both the providers/instructors and the adaptive OL systems must play an important role in reaching the goal of maximizing the advantages of OERs. For OER providers/instructors, especially MOOC teachers and course designers, they need to redesign their syllabi, break their entire courses into smaller units and pre-pack them with associated settings. For adaptive OL systems, the major problem is how to make OERs micro and guide learners to make accurate footsteps sustainably so as to form a resultful 
and fruitful footprint, this also being the main gap that we attempt to bridge in our work.

\subsection{Service-oriented Environment for Mobile OER Delivery}

A key catalyst for m-learning to thrive is the service-oriented and cloud computing paradigms, which harness economic benefits of large scale distributed systems, where computing resources are seamlessly integrated across geographical boundaries. Learners now have numerous options to make decisions for their own to access big learning resources, whenever they want, wherever they are.

In mobile environment, the system needs to provide learners with only the textual or visual learning material, but also software and apps, intuitive and task-oriented UI, clear and easy-to-follow operation logics, engaging experiences in associated courseware and learning settings. All of these are anticipated to be wrapped up and delivered in a one-stop mode. An ideal way to distribute such OERs is to deliver them as services. This can make the whole process of OER delivery user-transparent, and minimize the hardware requirement for mobile devices.

To build a comprehensive virtual learning environment (VLE) for learners to access OER via mobile devices, we design and deploy OER software as a service to provide learners with computational choices for smart OL. One of the major functions of this service is to execute a teamwork-enhanced learning flow for providing learners with better context for collaborative learning. This part of work is named Teamwork as a Service (TaaS) and has been reported in our previous study [28]. In this paper we focus on the rest of this system, targeting the conceptual and functional design and specifications for delivering micro OER to individual learners at their first conveniences. The detailed architecture of the system, Micro Learning as a Service (MLaaS) will be demonstrated in Section 5.

\section{MICRO OER}

\subsection{OER Categorization and Customization}

OER providers offer a number of options for training departments or educational institutes and agencies to implement micro learning paths within an organization, and for learners to build up their own learning schedules with a full of varieties and joys [29]. Some typical learning resources involve short videos and other visual learning resources, spaced repetition and practice activities, communication and collaboration environments, and credentials and gamification. Therefore, if micro learning resources are well-defined within short time length (i.e. 15 minutes), they are normally delivered right away.

However, most achievable MOOC contents are non-micro learning resources, which need to be refined properly. These contents need further processing and revision to fulfill micro learning demands, which can be instructor-led or computer-based.

The ultimate shapes of resources after processing are summarized as follows:

- Visual encyclopedia: Learning key points are listed out in terms of the knowledge structure of the entire course. For each key point, a video or textual material is set up without time limit to clearly illustrate the self-contained content. Because the content contained solely cover a particular scale, accordingly the required learning time is short.

- Logical segmentation of courseware and course videos: Herein each unit covers the complete information of a learning section, which includes the conditions of beginning and end, carries coherent contents, and can be studied individually.

- Extraction of sections from a complete course material: In this case the specific knowledge parts are selected and extracted in the first place while the redundant contents of the course are eliminated. Given many OERs with the same contents or knowledge scopes are offered from different OER providers, (e.g. a MOOC course for 'machine learning offered from Stanford University and Carnegie Mellon University ') the section extraction enables learners to learn in parallel, precisely locate the particular chapters, with no need to go through the whole course.

- Course-related and educational information in affiliated social media: This is a ramification of learning resources and also rich in educational values. This resource can be found not only in forums or blogs embedded in MOOC platforms, but also in other popular social media (e.g., Facebook, WeChat, Twitter, Tumblr, etc.), where learners, educators or external experts publish course-related materials [30]. A noticeable feature of this kind of resources is that its amount increases from time to time while some of the contents may contain pseudoscience or incorrect information [31][32].

- Subscription learning: from pedagogical view it is also been deemed as passive learning. As its name implies, it provides an intermittent stream of learning-related interactions to those who are 
subscribed. These learning-related interactions can involve a great variety of learning-related events, including content presentation, diagnostics, scenario-based questions, job aids, reflection questions, assignments, discussions, etc. Such interactions are short, intentionally scheduled overtime to support learning, often utilizing research-based findings related to the spacing effect. Learners subscribe one or more series of learning interactions can form as multiple learning threads [33].

- Two-way interactive contents or activity settings, ranging from feedback, assessment, review for contents generated by other learners, peer-to-peer learning, cooperative writing, collaborative work, and flipped classroom.

- Learner-generated contents: highly promoted by OL practitioners and educators, $p 2 p$ learning, digital flip classroom, mutual supervision are more and more of attached educational values in OL [34]. The new shape of MOOC which emphasis connectivist brings the acquisition and sharing of learner-generated contents into regular learning means [35] [36].

\subsection{Micro OER Measurement}

\subsubsection{Functional Attributes}

For modelling purpose, a learning resource chunk is considered to be measured with regards to the following features [37][38][39]:

- Time length

- Suitability for mobile learning

- Didactic model (inductive, deductive, learning by practice, etc.)

- Mediality (print media, electronic media, mono-media vs. multi-media, (inter-)mediated forms, etc.)

- Difficulty (level of knowledge)

- Completeness

- Requirement of attention

- Preferred learning styles

- Type of interaction (expositive, active, one-way imparted or two-way interactive)

- Requirement of input or hands-on practice

- Learning type: repetitive, activist, reflective, pragmatist, conceptionalist, constructivist, connectivist, and behaviorist; also: action learning, classroom learning, corporate learning, etc.

Also, a micro OER has its basic information such as topic, discipline, serial number, language it is taught, etc., which will be treated as the input of adaptation algorithm as well.

\subsubsection{Non-functional Attributes ( $Q o S)$}

These attributes describe the quality of services enclosed in the OERs system. We carry on the typical standards used in service oriented architecture, and listed some typical attributes that have more important influence on the delivery and user experience of micro OER [40]. These attributes involve:

- Performance (response time, latency, downtime, throughput)

- Reliability (availability, fault tolerance, recoverability)

- Robustness and stability

- Scalability and sustainability

- Compatibility, interoperability and adaptability

- Security

This part of responsibility is jointly taken over by an external service from main provider. MLaaS invokes its output and makes decision in conjunction with the adaptive results.

\section{Personalized Learner MOdel FOR Micro LeARning}

It is not difficult to track, monitor and record the entire process of a learner who accesses OERs. However, reporting them visually and statistically in order to reveal each learner's learning story is more crucial. This plays a significant role in conducting study ratiocination, judging learners' study status, estimating learners' study progress and carrying out learning strategy decision making. Finally, a dy- 
namic learner model for micro OL can be established by using these screened and sorted data [37], according to their historical and real-time data.

The data collection for building learner model can be realized in two ways: static data collection (e.g. from mandatory requests) and dynamic data tracking (e.g. from automatic extractions). The detailed learner features and learning context we intend to explore are listed in Section 4.1.

By investigating literature in the intersection of computer science and learning science, we have screened out features that play important role in the comfortability and success of micro OL. As shown in Figure 1, the learner model consists of two domains of factors (i.e. internal and external), while the internal factors can be classified into personal intelligent and non-intelligent factors. Each domain is enclosed by a rectangle outline and is distinguished by a particular color (i.e. external factors are in green rectangle, and internal factors are in black rectangle, where personal intelligent factors are in blue while Non-intelligent factors are in red). Some components can fall in the intersection of two domains which means these components are multi-correlated to two factors. Also, a component can be overlapped with others, which suggests that they are associated and mutually affected.

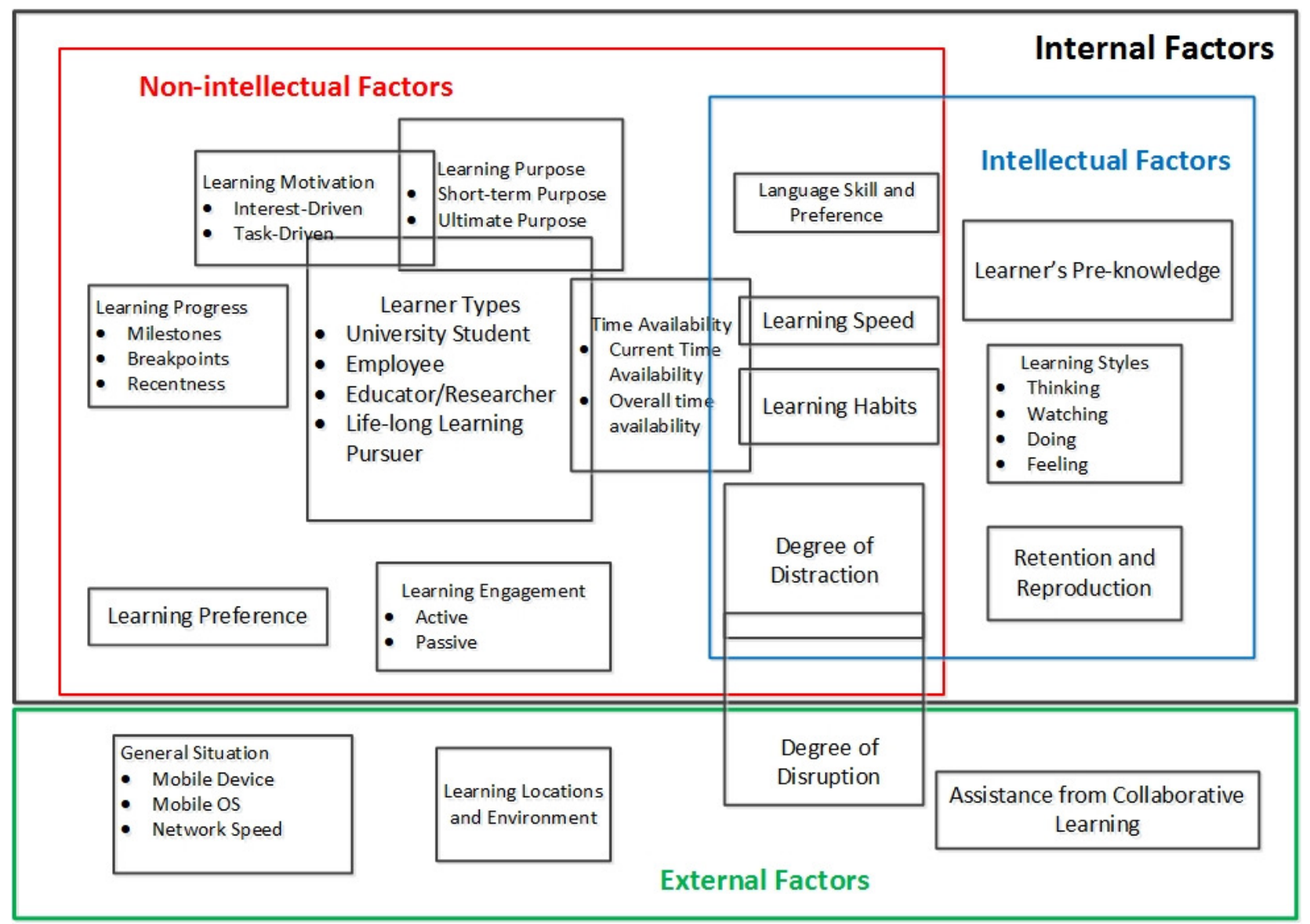

Figure 1. Personalized Learner Model for Micro MOOC Learning

\subsection{Components of Personalized Learner Modelling for Micro Learning}

\subsubsection{Personal Non-Intelligent Factors}

\section{Learner Types}

The types of MOOC learners vary evidently in accordance with their particular learning purposes and work, and life patterns. Their background information, though not always, can be searched from their registration and logon data [41] [42]. Some common types are:

- Full time students in universities who prefer to learn distantly and electronically rather than attend lectures in person. They are willing to enjoy the convenience brought by the smart and portal devices.

- Full time university students in developing countries where education is lower-developed. Because of scarce learning resources from their own universities, MOOC gives them greater oppor- 
tunities to remotely participate in classes provided by leading universities so that they can make step forward their daily learning and appreciate the advanced knowledge management and teaching approach.

- Educators who work in universities in developing countries. They take MOOC courses to obtain experiences from leading universities as well as learn how to teach in an efficient way to improve their own teaching approaches and flows.

- Researchers who are following up the flow of MOOC courses to explore potential defects in them, which result in barriers for learners to get knowledge passed on. Their goals are to refine the current MOOC teaching flows and to look for enhancing teaching approaches in a virtual manner. During the progresses when they are engaged in MOOC, pauses are frequently made and several specific sections of courses are retrieved repeatedly in terms of research demands.

- Employees who are required by their corporations or organizations to take MOOC courses for training purposes. Commonly they have a concentrate timeframe to complete MOOC courses. Their overall learning schedule is driven by their trainers and they have freedom to complete their allocated tasks continuously and arrange their time for each specific course units in place.

- Employees who wish to enrich their knowledge or improve their skills by taking MOOC courses in their off-work hours. Their final target is to become more competitive in workplace and they are generally self-motivated. So they set targets and milestones for each learning period by themselves with relatively more freedom and autonomy.

- Life-long learning pursuers. They can be employees whose learning contents in MOOC courses may not be closely related to their daily work, or they may be non-working persons such as housewives, elders or retired people [43]. Generally these kind of MOOC learners are interestdriven [44].

Time Availability

Learners' disposable time varies to a great extent, which is highly indicative for whether and how often these learners would adopt micro learning modes. So their current time availability is better to be set as a mandatory request for them to input before they start each micro learning activity.

Learning Engagement

The study [45] argues that the more engaged learners got higher marks in their MOOC courses. Most of their findings depend on analyzes of students' participations and publications in the education forums provided with MOOC platforms. They state that more engaged learners show more frequently in forums and are very positive to raise questions and attract other learners' interests to join their discussion regarding the learning contents. It does not mean they are lower-performing learners and contribute less in forums to seek useful advices and experiences, while the lowest-engaged learners even do not appear in the forums.

Past studies (e.g. [46] [47]) used quantitative methodologies to identify individual learner's engagement in MOOC and categorize them into cohorts in different ways. However, there lacks a unique definition for the extent of engagement of a learner. It is mainly measured in terms of a learner's total online time length, frequency of login, submission of required assignments, participation in forums, completion of courses or course chunks, etc.

Learners' engagement can also be categorized into active or passive learning. The former refers to that learners are self-motivated to attend virtual classes in MOOC platform so that they look for and initiatively access OL resources, which they need when they want; while the latter refers to that learners act as recipients of knowledge through information pushed by MOOC platforms or MOOC affiliated social medias, for example, they might have subscribed electronic reading materials.

Progress Identification

This is basically identified by breakpoints and milestones made by learners. In micro OL, learning activities become disperse, and the contents in two continuous learning phases can be not rigidly restricted in accordance with the sequences in the course curriculum. Learners' learning progress is not only confined into particular time points, but also categorized by taking their learning recentness into account. [14]

Learning Motivation and Purpose

Basically in OL learners are either interest-driven or task-driven. There learning purposes are identified by mandatory request data which means learner are suggested to input their learning purpose prior to the commencement of their OL.

Learning Preference

Learning preference refers to learners' subjective and affective opinion about learning contents. It can 
be sorted out through learners' comments and tags made on resources they have accessed.

\subsubsection{Personal Intelligent Factors}

Learner Pre-knowledge Assessment

To build a profile for each learner and customize micro learning strategy for learners with different backgrounds and basis, a measure that is necessary to take in prior is to assess each learner's background knowledge in terms of several standards. In micro OL, it is suggested to investigate and identify their pre-knowledge level in terms of the extent of their education, their historical courses grades in MOOC, and results of pre-course quizzes which are easy to be quantized.

A typical measure adopted by many e-learning systems is the pre-knowledge assessment [48] which refers to taking exams before learners commencing their courses. Although this is common to organize in on-campus courses, it is not feasible to directly migrant this into micro OL as learners are more distributed and on-the-go.

The outcomes of the pre-knowledge assessment are easy to be quantized. Hence, in micro OL, it is suggested to investigate and identify their pre-knowledge level in terms of:

- The extent of their education. This can give a general image of a learner's academic background and capabilities of acquiring new knowledge.

- Their historical courses grades in MOOC. This is to find learner's performance in related courses in order to build a reference to predict at what level s/he can commence a new course.

- Results of pre-course quizzes which are often in the form of multiple choices. It does not increase the difficulty of operation on mobile devices.

Learning Styles

Individuals differ in how they learn. Learning styles refer to the systematic differences in individuals' natural or habitual pattern of acquiring and processing information in learning situations.

According to [49], learning styles can be represented as concrete experience (feeling), reflective observation (watching), abstract conceptualization (thinking) and active experimentation (doing). However, because operations on mobile devices are relatively simple, which are limited in input and output methods, these four learning styles are difficult to be reflected straightway through monitoring learners' operation. Thus, identifying learners learning style requires extra efforts. For example, some external approaches are feasible to employ, such as self-evaluation. In addition, if learning activities in other MOOC courses are specified in terms of relevant learning styles, learners' performance in an exact learning activity can indicate their values on the corresponding learning styles.

Memory Ability

Memory ability can impact learning outcomes after the retention and reproduction stages of learning [50]. For OERs in the disciplines of culture, literature, arts, language and history, etc., memory ability is one of the key measures that can help learners transfer the contents of online MOOC resources into their own knowledge. It is particularly important when learning these disciplines using fragmented time pieces [51].

\subsubsection{Intersection of Non-Intelligent and Intelligent Factors}

\section{Learning Habits}

Each individual has a completely isolated structure of available time and learning time. Learning times for on-campus instructor-led learning mostly falls in day time. Unlike that, the mobile/micro OL time spread over all 24 hours of the day. Their personal situations affect their learning habits, which refer to, in this paper, how learners utilize their time on OL, in what way they get learning resources passed on, how often they make pause and repetition, after how long they take a review, whether they learn several MOOC courses in parallel, during what time stages in a day they are more often to make OL happen, and among those time stages, when they are more often intending to adopt micro learning means.

\section{Learning Speed}

This feature refers to the extent that learners spend in going through a course chunk and finishing related tasks on average. It can be estimated from their historical learning records.

Language Skill and Preference

Learners' language skills and preference should be taken into consideration to opt in/out their learning resources. Because most OERs are in English so that identification for learners' level of English skills is essential. Alternatively, this service investigates whether they are preferred to learn in their native languages or another second languages other than English.

Degree of Distraction 
Internally it concerns a learner's mood and emotion, and it is highly correlated to the degree of disruption, which is a component of the external factors [52] [53].

\subsubsection{External Factors}

Learning Locations and Environments

The ways how learners get connected to Internet apparently reveal their learning locations and surrounding environments. Generally in micro learning scenarios, they are brought to Internet through wireless networks by two means, namely Wi-Fi or mobile cellular network (e.g. 4G, 3G, and GPRS). Simply, connecting to internet through mobile network means learners are taking on learning activities ad hoc, the strength changes of the mobile signals can reflect their statuses of being on-the-go. The logon data of Wi-Fi portal may also determine learners' exact indoor learning places. Normally connecting Internet via Wi-Fi provided in public places rather than homes indicates learners are possible to experience higher frequency of interruptions as their surrounding environments can be more noisy and complicated.

\section{General Situation}

General situation regarding learning context partially affects their learning experiences and achievements. Information regarding the mobile devices and mobile OSs the learners utilized to carry out micro OL must be specified in order to determine devices capabilities, features and limitations [54].

Assistance from Collaborative Learning

Encouraged by the nature of how OL is structured and OERs' pedagogical concept, learners can get helpful information from P2P learning which can be collaborative learning, virtual social activities over social network and assimilating knowledge from content generated by other learners [55].

Degree of Disruption

The degree of disruption depends on the noise and interference factors from their surroundings, conflicts with their daily works, comfortableness with the setting and layout of the MOOC platforms and course design and so on [56].

\section{2 Pattern and Rule Discovery for Learner Model Construction}

\subsubsection{Methodology}

Student learning data collected by OL systems are being explored to develop predictive models by applying educational data mining methods that classify data or find relationships. These models play a key role in building adaptive learning systems, in which adaptations or interventions based on the model's predictions can be used to change what students experience next or even to recommend outside academic services to support their learning.

Analyzing these new logged events requires new techniques to work with unstructured text and image data, data from multiple sources, and vast amounts of data ("big data"). Big data does not have a fixed size; any number assigned to define it would change as computing technology advances to handle more data. So "big data" is defined relative to current or "typical" capabilities. For example, Manyika et al. (2011) defines big data as "Datasets whose size is beyond the ability of typical database software tools to capture, store, manage, and analyze.’[57]

At this cutting edge, educational data mining and learning analytics are widely used to research and build models in several areas that can influence online learning systems. As its name implies, EDM is 'a state-of-art that applies the data mining techniques to educational data' [58]. It is concerned with many developing methods, and acts on exploring the unique types of data in educational settings. Using these methods, students and the settings in which they learn can be better understood [58]. To enable smart and adaptive micro learning for MOOC, EDM and LA are key concepts that we employ to build the basis of the dynamic learner model construction.

\subsubsection{Stakeholders}

EDM and LA not only can help learners personalize their micro OL and recommend them activities, resources and even people they may have similar interests and targets to join as cohorts, but also can be of great significance for OL instructors and OER providers.

For OL instructors, EDM can help to get objective feedback about instruction; to analyze students' learning and behavior; to detect which students require support; to predict student performance; to classify learners into communities or groups; to find a learner's regular as well as irregular patterns; to find the most frequently made mistakes; to determine more effective activities; to improve the adaptation and customization of courses, etc. 
For OER providers and OL participant universities, EDM can help to enhance the decision processes; to streamline efficiency in the decision making process; to achieve specific objectives and enhance competitiveness among all OER providers; to suggest certain courses that might be significant for particular groups of learners; to find the most cost-effective way of improving retention and grades; to admit learners who will do well in open OL and attract more learners to engage in, etc.

Our EDM and LA will be jointly made by two parts, based on on-campus mobile learning data (i.e. structured data) and 'big' OL data (i.e. unstructured data).

\subsubsection{Data Sources for Identifying Learning Patterns and Understanding Learning Behaviors}

Along with our university, a public university in Australia, is initiating and releasing its own MOOC courses and OER online, in the current stage we are carrying out the experimental EDM and LA by substantially analyzing the real data of learning behaviors of students from our university in terms of the proposed EDM scheme. Such Data are collected from the department of Business Analysis and Learning Analytics of our university, and collated from its main learning management system and data warehouse. This analysis aims to identify the regular patterns of students getting involved in blended learning (i.e. on-campus learning and e/m learning), for example, whether and how often they adopt micro learning mode to accomplish learning tasks and what the major factors that affect their learning habits and, most importantly; and the rules of how features listed in the personalized learner model mutually affect and interrelate, and act on their learning outcomes. In other words, in this stage, we are discovering the potential trends, which cannot be directly shown from the data we can achieve, and then apply such findings into OL scene and infer what are behind the scene. The detailed data sets are illustrated in the following table.

Table 1. EDM/LA Data Sources

\begin{tabular}{|c|c|}
\hline Data type & Purpose \\
\hline $\begin{array}{l}\text { Learners' exact time of logon/out for each } \\
\text { time }\end{array}$ & To know how long they stay online for each time \\
\hline $\begin{array}{l}\text { The IP address or gateway information of } \\
\text { their internet connection }\end{array}$ & To know their exact learning location and surroundings \\
\hline Mobile OSs & To know their learning habits and general situation \\
\hline $\begin{array}{l}\text { Their personal enrollment information } \\
\text { (full time or part time, nationality) }\end{array}$ & $\begin{array}{l}\text { To know their learning time availability, organization, and lan- } \\
\text { guage skills }\end{array}$ \\
\hline $\begin{array}{l}\text { Their residential information (session ad- } \\
\text { dress and permanent address) }\end{array}$ & $\begin{array}{l}\text { To understand their distances to campus and the potential modes of } \\
\text { transportation they adopt) }\end{array}$ \\
\hline Subjects they chosen (current) & To know their academic background and field \\
\hline Subjects they chosen (historical) & To know their academic background and field \\
\hline Historical grades & To know their academic background and infer pre-knowledge level \\
\hline $\begin{array}{l}\text { Course materials they have accessed (ma- } \\
\text { terial type, topic, length, requirement as- } \\
\text { sociated with them) }\end{array}$ & $\begin{array}{l}\text { To know their learning habits (how they prefer the learning resources } \\
\text { to be passed on) }\end{array}$ \\
\hline $\begin{array}{l}\text { Course requirement/milestones set in } \\
\text { MOODLE (by instructor) }\end{array}$ & To know the suggested learning schedule \\
\hline Their detailed learning activities & $\begin{array}{l}\text { To know their learning habits, learning engagements, learning speed } \\
\text { and so on. }\end{array}$ \\
\hline $\begin{array}{l}\text { Their interactions with MOODLE and } \\
\text { learner-generated content (from forum and } \\
\text { thread, etc.) }\end{array}$ & To know their preference, interests and measure their engagement. \\
\hline $\begin{array}{l}\text { Frequencies of they participate in interac- } \\
\text { tive learning activities (e.g. forum, thread) }\end{array}$ & To know their engagement \\
\hline $\begin{array}{l}\text { Extent of completeness for each learning } \\
\text { activity }\end{array}$ & $\begin{array}{l}\text { To know whether they finished an entire step of learning or drop off } \\
\text { halfway }\end{array}$ \\
\hline $\begin{array}{l}\text { The learning paths they have gone through } \\
\text { (the sequence of they accessing learning } \\
\text { resources over MOODLE ) }\end{array}$ & To further establish optimal learning paths \\
\hline Their learning achievement & To know how their learning behaviors affect their learning outcomes \\
\hline Groups or teams they have participated in & $\begin{array}{l}\text { To know their collaborative learning performance and similari- } \\
\text { ties/changes of learning time frame among learners }\end{array}$ \\
\hline
\end{tabular}

\subsubsection{EDM and LA Scheme for OL Data (big data)}

Based on the prospective EDM/LA result, a meta-data standard will be built. It functions in digitalizing 
and formalizing the description of learner behaviors and external factors. It is responsible for the benchmark setting for the routine data extraction from OL platform. The study will be subsequently extended and applied into a larger scale, by analyzing 'big' data from real OL activities.

The EDM/LA types, objects and anticipated purpose for 'big' OL data are summarized in the following Table 2.

Table 2. EDM/LA Scheme for OL Data

\begin{tabular}{|c|c|c|}
\hline Type & Object & Purpose \\
\hline Prediction & $\begin{array}{l}\text { well-defined micro } \\
\text { OERs }\end{array}$ & $\begin{array}{l}\text { to establish a recommendation model for students in similar situations } \\
\text { in the future }\end{array}$ \\
\hline Structure Discovery & $\begin{array}{l}\text { well-defined micro } \\
\text { OERs }\end{array}$ & $\begin{array}{l}\text { for web documents using clustering methods in order to personalize e- } \\
\text { learning based on maximal frequent item sets }\end{array}$ \\
\hline $\begin{array}{l}\text { Latent Knowledge } \\
\text { Estimation }\end{array}$ & Non-micro OERs & $\begin{array}{l}\text { to discover which stages of them are generally finished within rela- } \\
\text { tively larger time length }\end{array}$ \\
\hline Structure Discovery & Non-micro OERs & $\begin{array}{l}\text { to determine time spans where the pauses made by learners usually } \\
\text { fall in }\end{array}$ \\
\hline Factor Analysis & Non-micro OERs & $\begin{array}{l}\text { to find out the reasons actually why learners spent more time on these } \\
\text { stages and made such pauses }\end{array}$ \\
\hline $\begin{array}{l}\text { Latent Knowledge } \\
\text { Estimation }\end{array}$ & Non-micro OERs & $\begin{array}{l}\text { to measure potential suitability of micro learning (from learners' fre- } \\
\text { quencies of using fragmented time pieces) }\end{array}$ \\
\hline Factor Analysis & Non-micro OERs & $\begin{array}{l}\text { to identify resources' suitability for micro learning, for example, } \\
\text { whether a hands-on practice is needed, or whether the OER delivery is } \\
\text { necessarily associated with lots of writing or computation work which } \\
\text { is inconvenient to complete on mobile devices }\end{array}$ \\
\hline Prediction & $\begin{array}{l}\text { Subscription of } \\
\text { OERs }\end{array}$ & $\begin{array}{l}\text { to determine when to push information to learners in the best timing } \\
\text { and remind them }\end{array}$ \\
\hline Clustering & All micro OERs & to determine their correlations for better repository purpose \\
\hline Relationship Mining & Time Availability & $\begin{array}{l}\text { to discover the correlation between their overall time availability and } \\
\text { learners types }\end{array}$ \\
\hline Clustering/Prediction & Time Availability & $\begin{array}{l}\text { to involve similar learners into cohorts and build potential time frame } \\
\text { for them overall learning schedule }\end{array}$ \\
\hline $\begin{array}{l}\text { Latent Knowledge } \\
\text { Estimation }\end{array}$ & $\begin{array}{l}\text { Learning habit } \\
\text { (learning time dis- } \\
\text { tribution) }\end{array}$ & $\begin{array}{l}\text { to discover whether there are regular patterns of time organization } \\
\text { within time frame among learners in or across cohorts }\end{array}$ \\
\hline $\begin{array}{l}\text { Latent Knowledge } \\
\text { Estimation }\end{array}$ & $\begin{array}{l}\text { learners' latest } \\
\text { learning contents } \\
\text { and activities }\end{array}$ & To retrieve back and profile learners' learning recentness \\
\hline Categorization & Learning habits & to set up a unique learning habit summary for each learner \\
\hline Relationship Mining & $\begin{array}{l}\text { Learners' learning } \\
\text { location data }\end{array}$ & $\begin{array}{l}\text { to know the degree of distraction and how it interrelates to disruption } \\
\text { from external environment, }\end{array}$ \\
\hline Relationship Mining & $\begin{array}{l}\text { Learners' mobile } \\
\text { app usage }\end{array}$ & $\begin{array}{l}\text { to know the degree of distraction and how it interrelates to disruption } \\
\text { from the content on mobile internet }\end{array}$ \\
\hline $\begin{array}{l}\text { Social Network } \\
\text { Analysis }\end{array}$ & $\begin{array}{l}\text { OERs in affiliated } \\
\text { social networks }\end{array}$ & $\begin{array}{l}\text { to distinguish information that can be useless, harmful and may cause } \\
\text { time wasted for learners. }\end{array}$ \\
\hline $\begin{array}{l}\text { Social Network } \\
\text { Analysis }\end{array}$ & $\begin{array}{l}\text { Other content in } \\
\text { affiliated social } \\
\text { networks }\end{array}$ & $\begin{array}{l}\text { to screen well-recognized information in order to recommend to } \\
\text { learners as their learning augmentation besides the OERs (text mining } \\
\text { technique employed) }\end{array}$ \\
\hline
\end{tabular}

\section{SyStem ArChitecture AND Working PrinCIPLE}

\subsection{Topology of OER delivery and Leaner Distribution in Virtual Open Learning Environment}

As aforementioned in Section 2.4, we devote to employ design science methods to overcome the above challenges so as to deliver learner customized learning resources, in the form of small chunks or finegrained units. We have proposed a SaaS, MLaaS, to enclose all our research ideas and attempts. The framework of MLaaS is shown in Figure 2. As a data-rich system, MLaaS will be able to exploit detailed learner activity data for not only recommending what the next micro learning activity for a particular student should be, but also predicting how that student will perform with future learning content. 


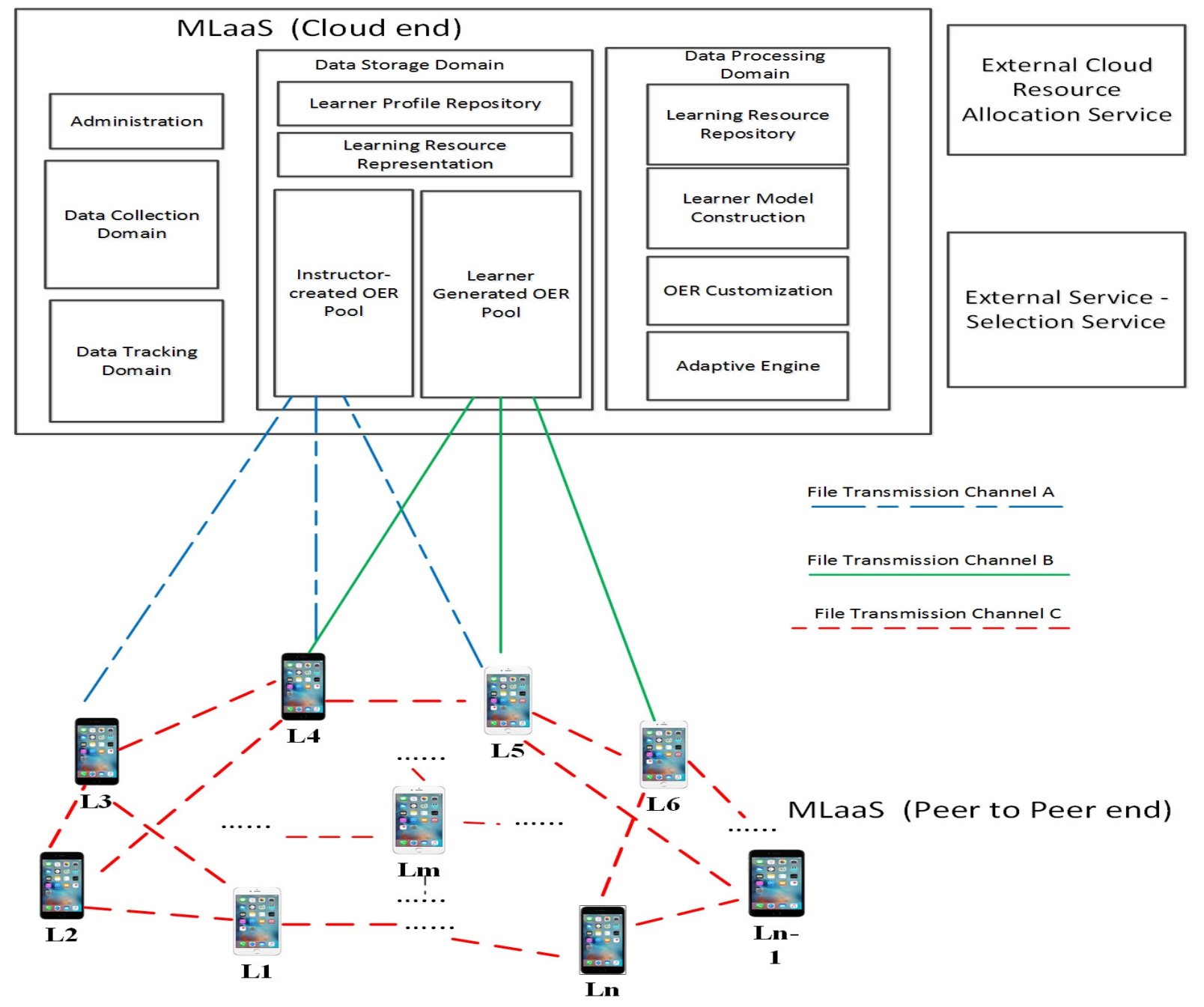

Figure 2. Topology of the Architecture of MLaaS

In our pilot work, we proposed a peer to cloud and peer-to-peer model for resource share and storage in service-oriented context [59]. Such model should have faster upload and download speed than traditional cloud/user model or peer-to-sever-peer model, and be more robust to the failures of peers or servers in the cloud environment [59]. Hence, we carry on this design and apply its concept as the topology of the new system for micro OL.

The $\mathrm{P} 2 \mathrm{P}$ sub-network of the proposed system is to conform with the natural of OL, where various $\mathrm{P} 2 \mathrm{P}$ learning occurs frequently and randomly. This $\mathrm{p} 2 \mathrm{p}$ tier guarantees that $\mathrm{P} 2 \mathrm{P}$ learning can be organized instantly, and the first hand resources can be shared and exchanged, regardless of the access of cloud.

From the top-down view, MLaaS borrow the cloud service to maximize the capability of hosting. Cloud part of the system consists of four domains: data tracking, data collection, data processing and data storage.

The data tracking domain works to actively track learner behaviors and gather real-time data. It goes deep into the length of each of their learning time pieces. Accordingly, the termination of each learning time piece can be further studied to be attributed to the end of learner's attention, time availability, unexpected distraction or other factors. These data are dynamic as they may vary from time to time along with the progress of OL.

The data collection domain works to collect data in static state, such as learners 'general information, and mandatory request, such as their instant time availability. These two domains work in conjunction to feed the data processing domain. In this domain, as discussed in Section 4.2, in addition to raw data pre-processing, the most important function of this domain comes from an EDM/LA service. It carries out the ongoing EDM/LA process, at the back of the learner modelling Service and micro OER customization Service. The former is responsible for the machine learning-based learner model construction, keeping the learner models up-to-date, whereas the latter handles the decision making proce- 
dure of OERs customization.

Instructor-created OERs are stored in the corresponding pool in the cloud end. Their profiles, which encompass the metadata semantically describing their functional attributes, have been recorded in the learning resource representation Service [60] [61]. The micro OER customization Service works to tailor OERs according to their time length and other suitabilities for micro learning. Newly segmented OERs will be re-described by metadata, which will then be refilled to the learning resource representation Service.

The learner-generated contents can be stored at either the cloud end or the user end. If they keep the files on their own devices without uploading it, their address information will be sent to cloud end and stored as tags. Data related to good-quality and mostly-followed/discussed learner-generated content, will be refilled into the learner-generated OER pool in order to support peer-to-peer learning in MOOC [62]. Links to course-related and educational information in affiliated social media are sorted and stored as tags in the pool as well.

The storage domain also holds a learner profile repository service, storing all generated personalized learner models.

Furthermore, in the Learning Resource Repository Service, selected course modules are clustered using text/data mining technologies. This service also measures correlations among chunks, or, if feasible, derives correlations from existing MOOC course modules. It helps set a 'big map' of knowledge scope, including the learning start point and exit point and resources, and identifies a learning path among them [63][64].

Hence there are three file transmission channels:

- A channel between learners and instructor-created OER pool in the cloud storage part (i.e. Channel A in Figure 2).

- A channel between learners and learner-generated OER pool in the cloud storage part (i.e. Channel B in Figure 2).

- A channel among all learners engaged in OL ((i.e. Channel $\mathrm{C}$ in Figure 2)).

Taking inputs from all the above services, the Adaptive Engine Service acts by providing learners with customized learning resources, which are based on a series rules discovered from EDM/LA, matching their current micro learning context, personal demands, learning styles and preferences. Recalling the theme of a recommender system, typically the inputs of its reasoning engine come from two sides: the user side and the item side. Hereby, in MLaaS, it consumes data describing learners and micro OERs, respectively, to solidly support the decision making of adaptation.

It is the core of the proposed system, which embeds machine learning technologies to realize the adaptive mechanism [65].

Once a learner shows his/her demand to carry out micro learning and sends such request from mobile device, micro OERs will be prepared through collaborations among services following a succinct workflow in the cloud end. An example collaboration is shown in Figure 3. Then, customized micro OERs will be transmitted through one of the three channels. 


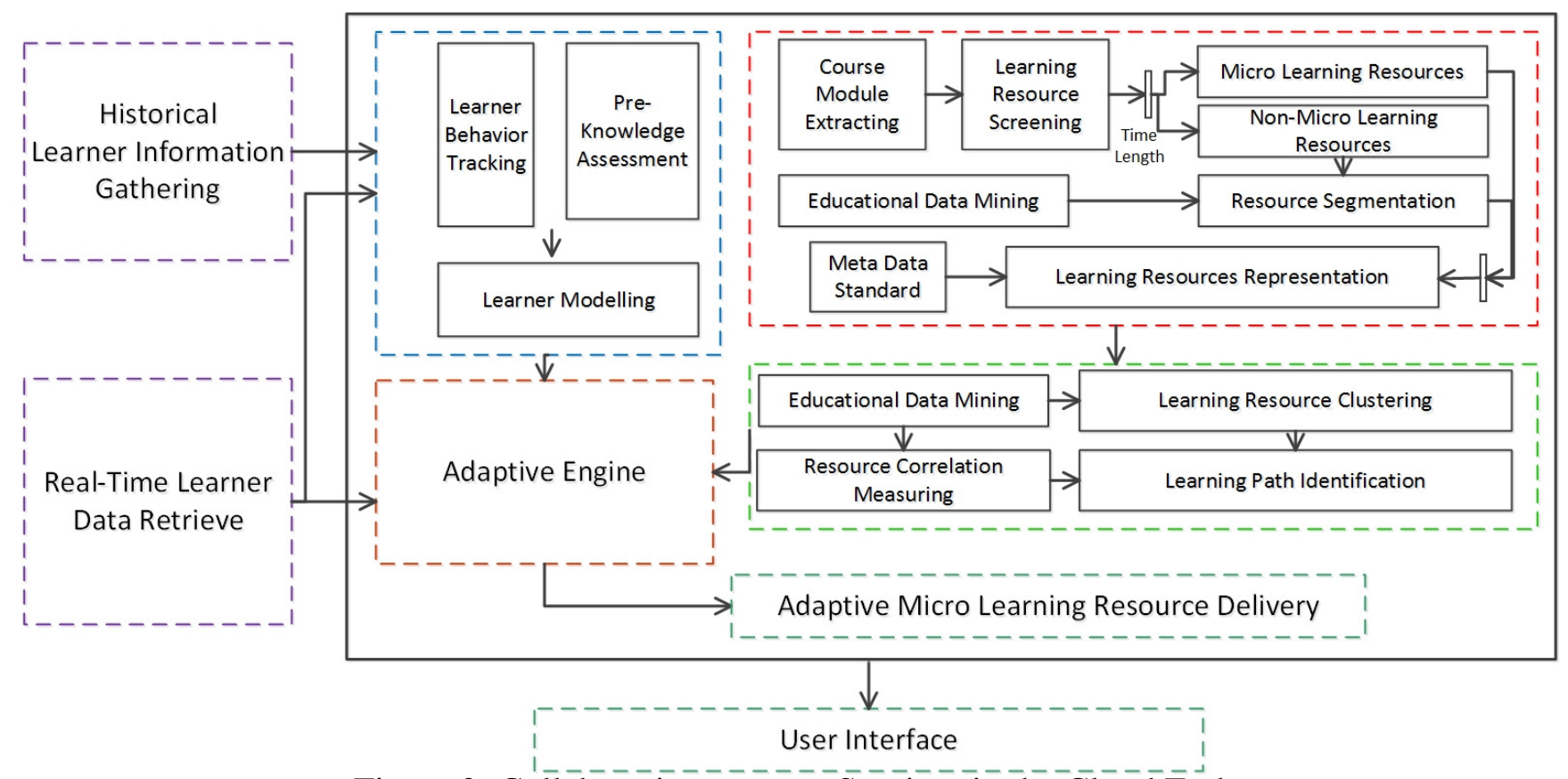

Figure 3: Collaborations among Services in the Cloud End

Where the OERs actually come from the cloud resources pools (from which exact cloud nodes the OERs are retrieved and invoked) will be defined and externally supported by third-party serviceselection and resource-allocation services from mainstream service providers. This problem has been well studied, typical solutions can be referred to the work reported in [66].

\subsection{Working Principle of Micro OER Adaptation and Architecture Specification for MLaaS}

The Adaptive process of OER consists of three processes, generating a big map, generating a learning path and recommending specific micro resources for an instant learning. As a key step of the micro OER delivery, a learning path optimization proposal has been reported in prior study [67]. The working principle of the overall flow is shown in Figure 4. 


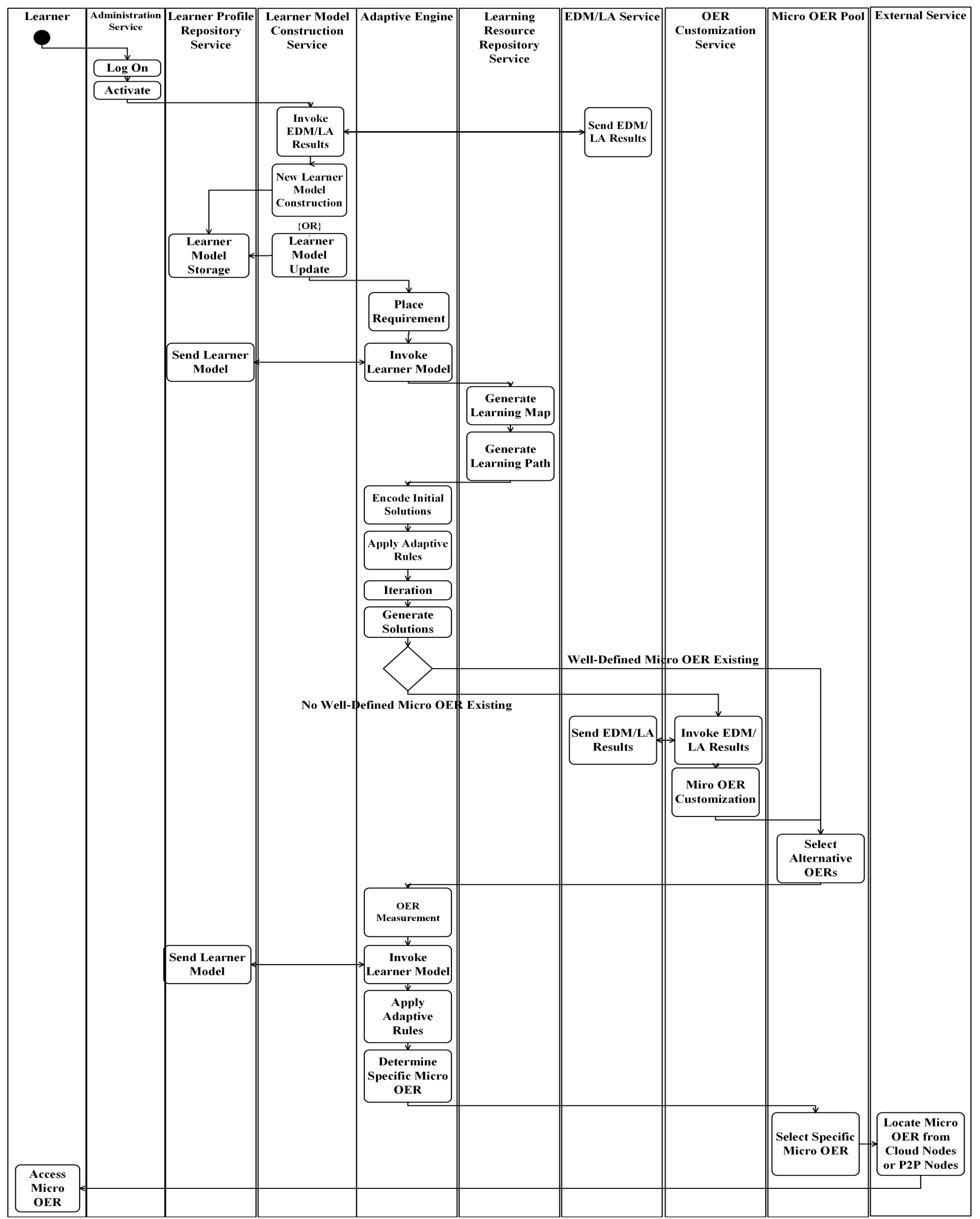

Figure 4. Working Principle of Micro OER Delivery

As aforementioned in Section 2.4, MLaaS is naturally service-oriented and performing in company with the TaaS [27]. MLaaS emphasis interactions with OER providers' platforms and educational institutions' learning management systems, and it exposes its functions for those systems as well as external services (e.g. service-selection and resource-allocation services) to call and then invoke.

To implement the service-oriented framework in a mobile cloud environment, and to minimize the cost and time of development, it is worthwhile to employ the amazon web service (AWS) to fulfill the 
requirement of hosting, storaging, computing and mobile-enabling. In this case, series of cloud services provided by AWS work in conjunction to build the comprehensive peer-to-cloud/peer environment for micro OL.

Technically, the cloud hosting part is taken charge by the Amazon elastic cloud computing (EC2), in which the EC2 block storage volumes (EBS) holds an instance for the entire system, comprising the extensible demand of CPU, memory, storage and network affiliated. Meanwhile the Auto Scaling and Elastic Load Balancing services work together with the EC2 Container service in order to adjust its volume and control internet traffic.

The information MLaaS deal with is snowballing with the fast generated data (i.e. from both historical and real-time sides) regarding OER production and learners learning behaviors in OL. AWS Import/export Snowball is ideal to utilize to addresses common challenges with large-scale data transfers including high network costs, long transfer times, and security concerns. Amazon S3 will be employed as the data storage because of its robustness and mature disaster recovery mechanisms.

Considering the interior of personalized learner model for micro OL, it is suggested to be deployed in the Amazon Rational Database service profiting from its resizable capacity in terms of real-time demand of data extraction and inference. Finally, the P2P tier of MLaaS is mapped out using Mobile Hub service from Amazon, which allows learners to create a personalized link and send it to peers for fast resource exchanges and transmissions through Channel C.

\subsection{Scenario Example of Micro OER delivery}

To better understand the micro OER delivery process, we conclude the contents from the section 4 and 5 and take the following typical scenarios and the activities involved in each as example:

It is 9am at morning and Jack is travelling to work by train. He utilizes the 20-minute journey to improve himself by taking an online course of 'business management' offered by a well-known open learning provider, edX. His mobile phone is empowered by a $4 G$ network. He is in a full carriage, surrounded by passengers who are chatting. MLaaS makes him reviewing a 5-page lecture notes followed by a multiple-choices with 20 questions in regards to the content in the lecture notes.

An undergraduate student Michael, who is enrolled in an Asian university, manages to extend his knowledge regarding the 'business intelligence'for which he takes a subject with the same topic in this semester. He links to a free Wi-Fi provided by a shopping center and turns on the MLaaS app while he is waiting for a friend. MLaaS direct him to a reading list posted by a leading US university and suggests him a specific article which contains several typical successful cases of business intelligence application.

At a short coffee-break of a session, Roger is trying to make up few points in his presentation content before delivering it. This presentation is about the future trend of eBusiness in Australia and he did a deep research on the topic of 'supply chain management' when he was preparing the presentation in the recent few days. Based on his learning history and progress, the system recommends him a partial section of a lecture video, with a focus on definition and concept of 'supply chain management' and a time length of 9 minutes, from the 'eBusiness' courseware available from an Australia open learning platform.

A retired elder Duncan wants to know more about the Italian history. He picks up his basic smart phone, say iPhone 4, while he is waiting for the ticking from the oven timer. MLaaS delivers him an audio of a brief introduction of 'Renaissance' and several photos of famous paintings and sculptures along with their audio commentary from the museum where they are kept.

A Japanese full-time staff is pursuing a degree of 'electronic engineering' online in the purpose of further promotion in his career. He collects credits from universities involved in Coursera. MLaaS jointly suggests him courses taught in English and Japanese. While he is logging into MLaaS using a tablet, he is introduced into a demo laboratory practice of 'signal processing'.

From the learners' perspective, by leveraging MLaaS, the most important benefit for them is that they are able to make use of fragmented pieces of time to achieve learning outcomes. Also, in the view of usefulness and ease of use of MLaaS, they can have their preferred OERs delivered instantly and accurately, which are expected to operate easily and run smoothly over mobile devices. An ideal micro OER delivered is easy to go through, neither too long to be with any unexpected pause or break-down, nor too short to leave any unfinished part to next available time.

\section{Conclusion}

The aim of our study is to bridge the gap between the promise of OL and the current limitations of OL by leveraging the concept of micro learning to maximize its advantages through offering learners better learning experience. Compared with the traditional approaches on adaptive mobile learning, from the 
time side we deepened our sight into a micro learning level, and from the space side we extended our view upto the open learning scale. Besides common features that play roles in enhancing learning experience and outcomes, we also take into account the potentially positive and negative effects that caused by the highly-mobile situation and tight time.

This idea was realized by a SaaS, MLaaS, which provides learners with adaptive micro OERs. The main contribution of our research is incorporation of a personalized learner model, a detailed scheme for conducting EDM/LA to understand micro learning patterns and rules, and the architecture of the system. We also illustrated the working principles of the adaptive OER delivery.

Our future work will include building an ontology to semantically capture the 'learning description' of a learner according to the proposed learner model and an AI-supported approach to computational implementing the adaptive process.

\section{REFERENCES}

[1] J. Baggaley, 'MOOC Rampant', Distance Education, vol. 34, no. 3 pp. 368-378, 2013.

[2] L. Pappano, 'The Year of MOOC', the New York Times, Published on November 2, 2012.

[3] I. Nawrot and A. Doucet, 'Building Engagement for MOOC Students: Introducing Support for Time Management on Online Learning Platforms', Proceeding of WWW'14 Companion, 2014, pp.1077-1082.

[4] I. Warrd, A. Koutropoulos, N. O. Keskin, S.C. Abajian, R. Hogue, C. O. Rodriguez and M. S. Gallagher, 'Exploring the MOOC Format as a Pedagogical Approach for m-learning', the 10th World Conference on Mobile and Contextual Learning, Beijing, China, October 2011.

[5] J. Hylen, D.V. Damme, F. Mulder and S. D' Antoni, 'Open Educational Resources: Analysis of Responses to the OECD Country Questionnaire', OECD Education Working Papers No. 76, June 2012.

[6] A. Trifonova and M. Ronchetti, 'Mobile Learning: Is Anytime + Anywhere = Always Online?' 6th IEEE International Conference on Advanced Learning Technologies, Kerkrade, Netherlands, July, 2006.

[7] J. Attewell, a Technology Update and m-Learning Project Summary, Mobile Technology and Learning, Learning and Skills Development Agency, UK, 2005.

[8] H. Wu, L. Hamdi and N. Mahe, 'Tango: A Flexible Mobility-enabled Architecture for Online and Offline Mobile Enterprise Applications', 11th International Conference on Mobile Data Management, Kansas City, MO, USA, May, 2010, pp.230-238.

[9] M. Ally and M. Samaka, 'Open Education Resources and Mobile Technology to Narrow the Learning Divide', The International Review of Research in Open and Distributed Learning, vol.14, no.2, pp. 15-27, 2013.

[10] K. Gutierrez, 'Mobile Learning: A Designer's Guide to Fighting Learner Distraction', Shift: eLearning-Disruptive eLearning, July 2014.

[11] G. Stockwell, 'Investigating Learner Preparedness for and Usage Patterns of Mobile Learning', ReCALL Journal of Cambridge University, vol. 20, no. 3, pp. 253270, 2008

[12] P.J. Guo, J. Kim and R. Rubin, 'How Video Production Affects Student Engagement: An Empirical Study of MOOC Videos', The 1st ACM Conference on Learning at Scale (L@S), Atlanta, Georgia, US, March 2014, pp.41-50.

[13] D. Kovachev, Y. Cao, R. Klamma and M. Jarke, 'Learn-as-you-go, New Ways of Cloud Based Micro-learning for the Mobile Web', 10th International Conference on Web-based Learning, Hong Kong, December 2011.

[14] P.A.Bruck, L.Motiwalla and F. Foerster, 'Mobile Learning with Micro-content: A Framework and Evaluation', 25th Bled eConference, Bled, Slovenia, 2012, pp.527-542.

[15] T. Hug and M. Lindner, 'ML: Emerging Concepts, Practices and Technologies after e-Learning', Proceedings of Micro Learning 2005, Austria, June 2005, pp. 8-11

[16] M. I. Souza and S. F. D. Amaral, 'Educational Micro content for Mobile Learning Virtual Environments', Creative Education, vol. 5, no. 9, pp. 672-681, 2014.

[17] A. L.Franzoni and S. Assar, 'Student Learning Styles Adaptation Method Based on Teaching Strategies and Electronic Media', Educational Technology \& Society, vol.12, no.4, pp. 15-29, 2009.

[18] M. Pinola, 'Mobile collaboration and community tools for virtual teams', in Gary Woodill (ed.), The Mobile Learning Edge, McGraw-Hill Companies, 2011.

[19] A. Kukulska-Hulme, M. Sharples, M. Milrad, I. Arnedilo-Sanchez and G. Vavoula, 'Innovation in Mobile Learning: A European Perspective', International Journal of Mobile and Blended Learning (IJMBL), vol. 1, no. 1, pp. 13-35, 2013.

[20] C. Guo, L. Wu, Q.Liu, J. Qin and J.Hu, 'Research on E-Learning Oriented Micro-Resources Organization and Generation Method', Hybrid Learning: Innovation in Educational Practices, Springer LNCS vol. 9164, pp. 349-358, 2015.

[21] M. Sarrab, N. Alalwan, O. Alfarraj, A. Alzahrani, 'An Empirical Study on Cloud Computing Requirements for Better Mobile Learning Services', International Journal of Mobile Learning and Organisation, vol.9, no.1, pp.1-20, 2015.

[22] G. Gassler, T. Hug and C. Glahn, 'Integrated Micro Learning-An Outline of the Basic Method and First Results', Interactive Computer Aided Learning, pp.1-7, 2014.

[23] S. Cakula and M. Sedleniece, 'Development of a Personalized e-learning Model using Methods of Ontology', Procedia Computer Science, vol.26, pp.113-120, 2013.

[24] P. Adamopoulos, 'What Makes a Great MOOC? An Interdisciplinary Analysis of Student Retention in Online Courses', $34^{\text {th }}$ International Conference on Information Systems (ICIS), Milan, Italy, December 2013, pp. 1-21.

[25] T. Daradoumins, R. Bassi, F. Xhafa, S. Caballe, 'A review on massive e-learning (MOOC) design, delivery and assessment', 8th International Conference on P2P, Parallel, Grid, Cloud and Internet Computing, October 2013.

[26] A. Al-Hmouz, A, J. Shen, R. Al-Hmouz and J. Yan, 'Modelling and Simulation of an Adaptive Neuro-fuzzy Inference System (ANFIS) for Mobile Learning', IEEE Transactions on Learning Technologies, vol.5, no.3, pp. 226-237, 2010.

[27] F.H. Wang, 'Content Recommendation Based on Education-Contextualized Browsing Events for Web-based Personalized Learning', Educational Technology \& Society Journal, vol. 11, no. 4, pp. 94-112, 2008.

[28] G. Sun and J. Shen, 'Facilitating Social Collaboration in Mobile Cloud-Based Learning: A Teamwork as a Service (TaaS) Approach', IEEE Transactions on Learning Technologies, vol. 7, no. 3, pp. 207-220, 2014.

[29] G. Lourdes, M. M. Albert, 'MOOC Design Principles: a Pedagogical Approach from the Learner's Perspective', eLearning Papers, pp.1-6, 2013.

[30] S. Mark, R. Williams, J. Mackness, 'Blogs and Forums as Communication and Learning Tools in a MOOC', the 7th International Conference on Networked Learning, Aalborg, Denmark, May 2010, pp.275-284.

[31] S. Dowling, 'Using Blogs to Share Learner-Generated Content, The Electronic Journal for English as a Second Language', vol. 17, no. 2, pp.1-22, 2013

[32] P.D.Henry, 'Using Mobile Apps and Social Media for Online Learner-generated Content', $10^{\text {th }}$ International Conference on Mobile Learning, Madrid, Spain, February 2014, pp.243.246.

[33] I. Waard, A. Koutropoulos, R. Hogue, S.C. Abajian, N. O. Keskin, C. O. Rodriguez and M. S. Gallagher, 'Merging MOOC and mLearning for Increased Learner Interactions', International Journal of Mobile and Blended Learning, vol. 4, no. 4, pp.34-46,2012. 
[34] M.J.W.Lee and C. McLoughlin, 'Teaching and Learning in the Web 2.0 Era: Empowering Students through Learner-Generated Content Mark', International Journal of Instructional Technology and Distance Learning, vol.4, no.10, pp.21-34, 2007.

[35] T. Cochrane, L. Antonczak and D. Wagner, 'Post-Web 2.0 Pedagogy: from student-generated Content to International Co-production', International Journal of Mobile and Blended Learning, vol. 5, no.4, pp. 1-18, 2013

[36] V. Narayan, 'Learner-generated Content as a Pedagogical Change Agent', Proceedings of the Ascilite 2011, Tasmania, Australia, December 2011, pp.891-903.

[37] A. Al-Hmouz, A, J. Shen, J. Yan and R. Al-Hmouz, 'Enhanced Learner Model for Adaptive Mobile Learning', The 12th International Conference on Information Integration and Web-based Applications and Service, Paris, France, November 2010, pp.783-786.

[38] S. Miranda and G. Albano, 'Personalized Learning in Mathematics', Journal of E-learning and Knowledge Society, vol. 11, no.1, pp.25-42, 2015.

[39] F. Bouarab-Dahmani, C. Comparot, M. Si-Mohammed and P.J. Charrel, 'Ontology Based Teaching Domain Knowledge Management for E-learning by Doing Systems', Electronic Journal of Knowledge Management, vol. 13, no.2, pp. 155-170, 2015.

[40] K.A.Alama and R. Ahmad, 'A Hybrid Fuzzy Multi-criteria Decision Model for Cloud Service Selection and Importance Degree of Component Services in Service Compositions', $12^{\text {th }}$ International FLINS Conference, Roubaix, France, August 2016, PP.334-340 .

[41] J. DeBoer, G. S. Stump, D. Seaton and L. Breslow, 'Diversity in MOOC Students' Backgrounds and Behaviors in Relationship to Performance in 6.002x', 6th International Conference of MIT's Learning International Networks Consortium (LINC), Cambridge, Massachusetts, June 2013.

[42] J. Kay, P. Reimann, E. Diebold and B. Kummerfeld, 'MOOCs: So Many Learners, So Much Potential', IEEE Intelligent Systems, vo. 28, no.3, pp.70-77, 2013.

[43] L.M.Blaschke, 'Heutagogy and Lifelong Learning: A Review of Heutagogical Practice and Self-Determined Learning' The International Review of Research in Open and Distributed Learning', vol. 13, no. 1, pp. 57-71, 2012.

[44] T. Cochrane, L. Antonczak and D. Wagner, 'Post-Web 2.0 Pedagogy: from student-generated Content to International Co-production', $11^{\text {th }}$ International Conference on Mobile and Contextual Learning, Helsinki, Finland, October 2012, pp. 156-163.

[45] A. Anderson, D. Huttenlocher, J. Kleinberg and J. Leskovec, 'Engaging with Massive Online Courses', the 23rd international conference on World wide web (WWW), Seoul, Korea, 2014, pp.687-698.

[46] C. Milligan, A. Littlejohn and A. Margaryan, 'Patterns of Engagement in Connectivist MOOCs', Journal of Online Learning and Teaching, vol.9, no. 2, pp.149-159, 2013.

[47] C. Alario-Hoyos, M. Perez-Sanagustin, C. Delgado-Kloos, H.A.Parada, M. Munoz-Organero, 'Delving into Participants' Profiles and Use of Social Tools in MOOCs', IEEE Transactions on Learning Technologies, vol. 7, no. 3, pp.260-266, 2014.

[48] D. Xu, W. W. Huang, H. Wang and J. Heales, 'Enhancing e-learning Effectiveness Using an Intelligent Agent-supported Personalized Virtual Learning Environment: An Empirical Investigation', Information and Management, vol.51, no.4, pp.430-440, 2014.

[49] A. Y. Kolb and A. D. Kolb, 'Learning styles and learning spaces: Enhancing experiential learning in higher education'. Academy of Management Learning and Education. vol.4, no.2, pp193-212, 2005.

[50] D.C.Bui and J. Myerson, 'the Role of Working Memory Abilities in Lecture Note-taking', Learning and Individual Differences, vol.33, pp.12-22, 2014.

[51] J. Xiong, 'Research on the Use of Mobile Learning to Teach English', International Conference on Social Science and Technology Education, China, April 2015.

[52] V. P. Dennen and S. Hao, 'Intentionally Mobile Pedagogy: the M-COPE Framework for Mobile Learning in Higher Education', Technology, Pedagogy and Education, vol. 23, no. 3, pp.397-419, 2014

[53] F. Khaddage, R. Christensen, W.Lai, G. Knezek, C. Norris and E. Soloway, 'A Model Driven Framework to Address Challenges in a Mobile Learning Environment', Education and Information Technologies', vol. 20, no. 4, pp. 625-640, 2015.

[54] R.A.W. Tortorella and S. Graf, 'Personalized Mobile Learning via an Adaptive Engine', the 12th IEEE International Conference on Advanced Learning Technologies, Roma, Italy, July 2012, pp. 670-671.

[55] H. Ji, K. Park, J. Jo and H. Lim, 'Mining Students Activities from a Computer Supported Collaborative Learning System based on Peer to Peer Network', Peer-toPeer Networking and Applications, vol.9, no.3, pp.465-476.

[56] C. M. Christensen, S. Aaron and W. Clark, 'Disruption in Education', The Internet and the University, pp.19-44. 2003.

[57] J. Manyika, M. Chui, B. Brown, J. Bughin, R. Dobbs, C. Roxburgh and A.H. Byers, 'Big data: The Next Frontier for Innovation, Competition, and Productivity', McKinsey Global Institute, 2011.

[58] C. Romero and S. Ventura, 'Educational Data Mining: a Review of the State-of-the-Art', IEEE Transactions on Systems, Man, and Cybernetics-Part C: Applications and Reviews, vol.40, no. 6, pp. 601-618, 2010.

[59] Z. Sun and J. Shen, 'A high performance peer to cloud and peer model augmented with hierarchical secure communications', Journal of Systems and Software, vol. 78, no. 7, pp.1790-1796, 2013.

[60] K. Veeramachaneni, F. Dernoncourt, C. Taylor, Z. Pardos, Z. and U. O'Reilly, 'MOOCdb: Developing Data Standards for MOOC Data Science', Artificial Intelligence in Education Workshops, July 2013.

[61] G. Beydoun, 'Formal Concept Analysis for an e-learning Semantic Web', Expert Systems with Applications, vol. 36, no.8, pp. 10952-10961, 2009.

[62] Y. B. Bouyia and S. Demetriadis, 'Peer-monitoring vs. Micro-script Fading for Enhancing knowledge Acquisition When Learning in Computer-supported Argumentation Environments', Computers and Education, vol. 59, no.2, pp. 304-315, 2012.

[63] C. M. Chen, 'Intelligent Web-based Learning System with Personalized Learning Path Guidance', Computers and Education, vol. 51, no. 2, pp. 787-814, 2008.

[64] V. Tam, E. Y. Lam and S. T. Fung, ‘Toward a Complete e-learning System Framework for Semantic Analysis, Concept Clustering and Learning Path Optimization', 12th IEEE International Conference on Advanced Learning Technologies (ICALT), pp. 592-596, Roma, Italy, July, 2012.

[65] P. Markellou, I. Mousourouli, S. Spiros and A. Tsakalidis, 'Using Semantic Web Mining Technologies for Personalied e-learning Experiences', Proceeding of the Web-based Education, Grindelwald, Switzerland, 2008, pp. 461-826.

[66] L. Wang and J. Shen, 'Multi-phase ant colony system for multi-party data-intensive service provision', IEEE Transactions on Service Computing, vol. 9, no. 2, pp. 264-276, 2016.

[67] G. Sun, T. Cui, S. Chen, W. Guo and J. Shen, 'MLaaS: A Cloud Based System for Mobile Micro Learning in MOOC', The 4th IEEE International Conference on Mobile Service (MS), New York, US, July 2015, pp.120-127. 
